\title{
INVENTARIO DE RECURSOS TURÍSTICOS COMO BASE PARA LA PLANIFICACIÓN TERRITORIAL EN LA ZONA ALTIPLANO DE SAN LUIS POTOSI, MÉXICO'
}

\author{
Paloma Blanco López* \\ Valente Vázquez Solís** \\ Juan Antonio Reyes Agüero*** \\ Universidad Autónoma de San Luis Potosí. México \\ Mauricio Genet Guzmán Chávez*** \\ El Colegio de San Luis, A.C., San Luis Potosí, México
}

\section{RESUMEN}

Este artículo aborda el análisis del potencial turístico como condición para la planificación turística. Se explica el turismo como factor de desarrollo y a la planificación como instrumento de su gestión. Se utilizan los municipios con mayor potencial turístico en la Zona Altiplano de San Luis Potosí para exponer y ejemplificar los resultados del diagnóstico de la región. Después se evalúan los instrumentos vigentes de planificación turística vigentes en San Luis Potosí y se ofrece una propuesta de aprovechamiento turístico con ayuda de un análisis FODA para los municipios seleccionados.

Recibido: 18 de julio de 2013

Devuelto para su revisión: 10 de enero de 2014

Aceptado: 12 de septiembre de 2014

* Programas Multidisciplinarios de Posgrado en Ciencias Ambientales (PMPCA), Universidad Autónoma de San Luis Potosí (UASLP), México. E-mail: pblanco77@ @otmail.com

** Facultad de Ciencias Sociales y Humanidades (FCSyH). Universidad Autónoma de San Luis Potosí (UASLP), México. E-mail: vazquezsv@uaslp.mx

*** Instituto de investigación de Zonas Desérticas (IIZD). Universidad Autónoma de San Luis Potosí (UASLP), México.

****El Colegio de San Luis, A.C., San Luis Potosí, México.

1 Este documento es resultado del proyecto de investigación: «Planificación del turismo sustentable en la Zona Altiplano de San Luis Potosí. Una propuesta metodológica», del Programa de Doctorado en Ciencias Ambientales de los Programas Multidisciplinarios de Posgrado en Ciencias Ambientales (PMPCA), Universidad Autónoma de San Luis Potosí (UASLP), México. Financiamiento CONACyT. Investigadora principal: Paloma Blanco López. 
Palabras clave: Recurso turístico natural, patrimonio turístico, planificación, desarrollo turístico, Zona Altiplano.

\title{
Inventory of tourism resources as a basis for territorial planning in Zona Altiplano of San Luis Potosi, Mexico
}

\begin{abstract}
This paper focuses on the analysis of tourist potential as a condition for tourism planning. It talks about the tourism as a factor of development and planning as a management tool. Municipalities with the greatest tourist potential in the highland area of San Luis Potosí are used to explain and illustrate the results of the diagnosis of the region. Then, existing tourism planning instruments in force in San Luis Potosí are evaluated and a proposal for tourist use with the help of a SWOT analysis for the selected municipalities is offered.
\end{abstract}

Key words: Natural tourist resource, heritage tourism, planning, tourist development, Zona Altiplano.

\section{INTRODUCCIÓN}

El turismo es una actividad que se relaciona con el bienestar económico al ser una de las principales fuentes de divisas y un detonador de desarrollo local que fomenta fuentes de empleo y diversifica las actividades económicas (INEGI, 2013b; OMT, 2013). Debido a eso, el Estado implementa proyectos, políticas públicas y una planificación que involucra los diferentes ámbitos de gobierno y una diversidad de actores públicos y privados, a través de planes de desarrollo turístico y programas sectoriales nacionales, regionales y/o municipales. (Blanco, 2008; Chávez, 2005; OMT, 2001; Osorio, 2006; Schulte, 2003).

Con la crisis del modelo tradicional de desarrollo acaecido a partir de la década de 1960 hasta su replanteamiento en 1987 (Pierri, 2001), se agrega al turismo una discusión teórica y práctica. En el aspecto teórico, se hicieron notar los daños ambientales que el turismo provocaba en los espacios receptores y se le identificó como ejemplo típico del crecimiento económico del siglo XX que no respetó los recursos ambientales, sociales y culturales en los que se sustentaba. Algunos ejemplos son el caso Torremolinos en España, los Beach Resorts en México (SECTUR, 2007) y una amplia gama de casos en Europa y El Caribe descritos en Knowles y Curtis (1999) y Cicin-Sain y Knetch (1998), quienes documentan los efectos negativos del turismo de masas.

En el aspecto práctico, aparece un visitante conservacionista e informado y turistas que buscaban una alternativa a los grandes espacios urbanos o de masas, lo que se tradujo en nuevas modalidades de demanda turística que «se orientan fundamentalmente hacia la valoración de los aspectos ambientales del destino, la autenticidad cultural y la calidad del producto» (OMT, 1996:13) y que en el ámbito local representaron oportunidades de desarrollo. 
A partir de la Conferencia sobre el Medio Ambiente y el Desarrollo de Río de Janeiro en 1992; y la Conferencia Mundial de Turismo Sostenible en Lanzarote, en 1995, los países se adhieren a acuerdos jurídicamente vinculantes como la Agenda 21 para la Industria de los Viajes y el Turismo (OMT, 1996) y la Carta del Turismo Sostenible (OMT, 1995) que establecen las directrices para el diseño de las políticas y acciones del desarrollo turístico sostenible, entendido éste como aquél «que atiende las necesidades de los turistas actuales y de las regiones receptoras, al tiempo que protege y fomenta las oportunidades para el futuro [...] una vía hacia la gestión de todos los recursos de forma que puedan satisfacerse las necesidades económicas, sociales y estéticas, respetando al mismo tiempo la integridad cultural, los procesos ecológicos esenciales, la diversidad biológica y los sistemas que sostienen la vida» (OMT, 1996).

Desde entonces se constata la incorporación de la planificación ${ }^{2}$ sostenible del turismo a nivel local y regional en países latinoamericanos. (Chávez, 2005; Cornejo, 2009; De Gomes, 2007; Salinas y La O, 2006). Sin embargo, la ambigüedad teórica y conceptual del término, el uso de modelos diseñados para contextos políticos, económicos y ambientales distintos y la tradición de una planificación primordialmente económica y sectorial provocan que la sostenibilidad sea utilizada en el discurso como mejor convenga para legitimar políticas que no necesariamente toman en cuenta las características físicas del territorio y las formas de organización social, económica y política locales (OMT, 2006; Morales 2012; Seguí, 2006). En consecuencia, la acción pública no logra vincularse con las necesidades de las regiones y los proyectos implementados constituyen una receta para el desastre. ${ }^{3}$

En cuanto al espacio turístico, los nuevos modelos de planificación conciben al territorio como un producto turístico integral que suma paisaje, empresas, infraestructuras, equipamientos, entorno social, patrimonio, etc. $\mathrm{y}$ «se destaca en forma rigurosa la toma en consideración de la disponibilidad de los recursos existentes». (OMT, 2006: 34). Esto es importante, ya que podría considerarse que cualquier territorio ${ }^{4}$ puede convertirse en un destino turístico en virtud de poseer recursos potencialmente atractivos, sin considerar que no todos cuentan con la capacidad material y física para atender a un creciente número

2 En la teoría sobre la administración pública se entiende por planeación a la acción de trazar un plan a corto plazo y se identifica con los planes quinquenales de la URSS. La planificación se refiere al plan que se proyecta a mediano y largo plazo para alcanzar objetivos determinados y se relaciona con la teoría de sistemas. En esta investigación se usa el término planificación en apego a la doctrina de la administración pública moderna.

3 Itziar Morales (2012) demostró empíricamente los efectos de la implementación institucional de un proyecto ecoturístico en la comunidad del Realejo, S.L.P., que no se ocupó de conocer los procesos políticos y sociales del contexto local y que tuvo como consecuencia un desapego colectivo hacia el proyecto, la polarización de los participantes y fricciones en las relaciones de poder de la comunidad. Por su parte, Miguel Seguí (2006) a través de un estudio de caso, plantea las dificultades encontradas en un proyecto de cooperación para la selección del modelo turístico más apropiado para las comunidades de la Ruta de Sandino al norte de Nicaragua. Entre otros aspectos, el autor pone de manifiesto la dificultad de combinar los intereses y visiones de distintos organismos y comunidades y el fracaso de los modelos de turismo en países en vías de desarrollo a través de la cooperación.

4 Bajo la perspectiva teórica de Gross (1998) y Ortega (2000), en esta investigación se entiende territorio como el espacio-región que trasciende al lugar concreto en donde se ubican los elementos singulares del espacio habitado, vivido, percibido, delimitado y de interacción de los subsistemas natural, social y económico. A su vez, se entiende espacio turístico, como la parte del territorio donde se localizan los elementos que están relacionados con la actividad turística y que pueden ser aprovechados para formar productos (Requejo, 2004). 
de visitantes, ni todos pueden desarrollarse en un plan turístico a largo plazo. De hecho, «algunos de ellos son tan vulnerables que la actividad turística puede traer beneficios sólo a corto plazo y a cambio de la destrucción de su base natural» (Bote, 1990:122).

Para realizar la selección de los recursos disponibles de un territorio es necesario identificar los lugares de interés turístico, inventariarlos y tipificarlos para posteriormente, seleccionar aquellos que se consideren prioritarios y en los cuales se ha de concentrar los programas y proyectos públicos y privados (Bote, 1990). En este contexto, este documento se ocupa de argumentar la necesidad de un diagnóstico de los recursos naturales y culturales con potencial turístico en un territorio, como una de las condiciones inherentes de una planificación turística integral.

Para ejemplificarlo, se muestra una parte de los resultados del inventario realizado sobre el patrimonio turístico natural y cultural de la Zona Altiplano de San Luis Potosí, a partir de una investigación documental complementada con trabajo de campo en donde se incorporó y adecuó la metodología de Romero (1986); Gutiérrez (1986); la Organización de los Estados Americanos (OEA) (En Bote, 1990) y Bote (1990), para la realización de inventarios turísticos. El diagnóstico aquí propuesto trata de demostrar que la Zona Altiplano de San Luis Potosí cuenta con un patrimonio turístico diversificado y con alto potencial para desarrollarse en un modelo de planificación turística.

\section{TURISMO COMO FACTOR DE DESARROLLO ECONÓMICO}

Al hablar del turismo como un instrumento de desarrollo económico es necesario argumentar sobre la economía ambiental, la economía ecológica, la economía social y la ecología política (Bote, 1990; Sachs, 1997; PNUMA, 2003; Daly, 1997; Guimarães, 2010; Leff, 2007; Morales, 2012). Cada una de estas posturas teóricas concibe el desarrollo desde una perspectiva particular y al ser adoptada por los Estados, la planificación de la actividad turística se ajustará a la estrategia global de desarrollo elegida. En este apartado se describen los planteamientos de cada postura teórica, su relación con el desarrollo turístico y finalmente, se selecciona aquella que se ajusta a los objetivos de este trabajo.

La economía ambiental apoya un sistema de libre mercado que combina facilidades a la iniciativa privada con mecanismos estatales destinados a corregir las fallas del mercado y las externalidades negativas (ecotasas, instrumentos económicos, análisis costo-beneficio) (Bote, 1990; Sachs, 1997; PNUMA, 2003). Para este enfoque, el desarrollo se basa en un crecimiento económico con cierto nivel de conservación de recursos naturales, cuidado ambiental y distribución de la renta, evitando o disminuyendo en lo posible, los costos económicos que suponen la escasez de recursos y la degradación ambiental (Pierri, 2001).

Bajo esta perspectiva, el turismo se relaciona con los objetivos generales de la economía nacional y sus metas son atraer un máximo número de visitantes, prolongar su permanencia y asegurar su regreso, a fin de lograr un consumo importante de bienes y servicios que se vincularán con otros sujetos relevantes (sector público, beneficios empresariales), bajo razonables controles estatales (Bote, 1990; Morant et al, 1996).

Por su parte, la economía ecológica establece una relación entre límites físicos y el desarrollo, en donde la productividad del capital se ve cada vez más limitado por la decreciente disponibilidad de capital natural (Daly, 1997 citado en Pierri, 2001: 70). 
A diferencia de la economía ambiental, el interés por mantener el capital natural no se limita a evitar costos económicos, sino que es una condición para que sea posible el crecimiento socioeconómico de la población (Pierri, 2001; Martínez y Roca, 2006). Para esta postura, el desarrollo implica no sólo la consolidación de los procesos productivos, sino también la preservación de los recursos naturales que afirmen y den continuidad a las actividades económicas. La aplicación de este modelo busca consolidar el turismo como factor de desarrollo económico en el ámbito local, al tiempo que logra la preservación del patrimonio natural y cultural que le sirve de base y que le permitirá dar continuidad a la actividad turística.

En otro orden de ideas, la economía social se orienta al mercado, pero también vincula el desarrollo con el medio ambiente, la naturaleza, el enfoque de género, la recuperación cultural, el combate a la pobreza, la participación social y las políticas públicas que respondan a las necesidades de las poblaciones, localidades y/o territorios. El desarrollo en este enfoque es concebido como una herramienta de las comunidades para formar parte de su propio crecimiento a partir de sus valores, ideales y forma de vida. En este modelo, el desarrollo turístico no se impulsa unilateralmente por el Estado, sino que se genera en las localidades a partir de la capacidad de éstas para ofrecer sus recursos naturales y culturales como productos turísticos (Guimarães, 2010). El resultado es la interacción entre los actores sociales, privados e institucionales a través del ordenamiento territorial y la democracia participativa (Zizumbo, 2010).

Una vertiente más se conoce como ecología política, cuyo objeto de estudio son las relaciones y conflictos entre los actores sociales involucrados en el control y acceso a los recursos naturales. Este modelo analiza el turismo a partir del conocimiento de los procesos políticos, simbólicos y disputas sociales alrededor de los actores sociales y la toma de decisiones colectivas, las cuales deben tomarse en cuenta por el Estado, pues lo contrario agudizaría los conflictos y favorecería la iniquidad en la asignación de los beneficios del desarrollo turístico (Leff, 2007; Morales, 2012).

Uno de los objetivos de este documento es analizar los recursos naturales en una región específica como una condición para favorecer el desarrollo turístico a largo plazo. Es por eso que en este trabajo se adopta el criterio de la economía ecológica para argumentar teóricamente sobre la importancia de categorizar y conservar los recursos naturales y culturales que constituyen el sustento y continuidad de la actividad turística en la Zona Altiplano de San Luis Potosí.

\section{LA PLANIFICACIÓN DEL TURISMO}

El cambio de paradigma en el desarrollo turístico obligó al Estado a adoptar y combinar modelos que se ajustaran a las nuevas tendencias y que dependían de la rigidez o flexibilidad de los procesos de gestión en cada lugar. Acerenza (2007) señala que esta problemática es fácil encontrarla en países en vías de desarrollo o subdesarrollados, en donde prevalecen los modelos económicos enfocados en la oferta-demanda y en los que, en el mejor de los casos, se usa el turismo sostenible como un instrumento de política ambiental para controlar o reducir impactos, o para reactivar las señales visibles de la cultura local. En nuestra opinión, los objetivos de coordinación e integración de los aspectos ambien- 
tales, sociales, culturales, institucionales y económicos en un esquema de planificación, aún no se resuelven ni resultan satisfactorios.

En forma general, la planificación turística se define como el proceso racional, ordenado y sistemático para gestionar y alcanzar el desarrollo y crecimiento turísticos (Cebrián, et al., 2001; Pardellas y Padín, 2004; Schulte, 2003). Para tal efecto, varios son los modelos propuestos: desarrollista (Molina, 1986); económico (Bote, 1990); estratégico (Ivars, 2003); urbanístico (Lawson y Baud-Bovy, en Acerenza 2006); de política económica (Hernández, en Acerenza 2006); comunitario (Getz, en Ivars, 2003) y regional (Gunn, 1979). Este último es «una propuesta para el contexto regional, tomando como base el análisis de zonas (...) con un énfasis en la expresión cartográfica para la definición de los conceptos de desarrollo» (Osorio, 2006:301). Se trata de un enfoque para la planificación local que parte de un detallado análisis físico de los recursos turísticos, la identificación de áreas potenciales de desarrollo turístico y que culmina con una propuesta de desarrollo, políticas y asignación de prioridades. (Figura 1).

Figura 1

\section{MODELO DE PLANIFICACIÓN REGIONAL DE GUNN}

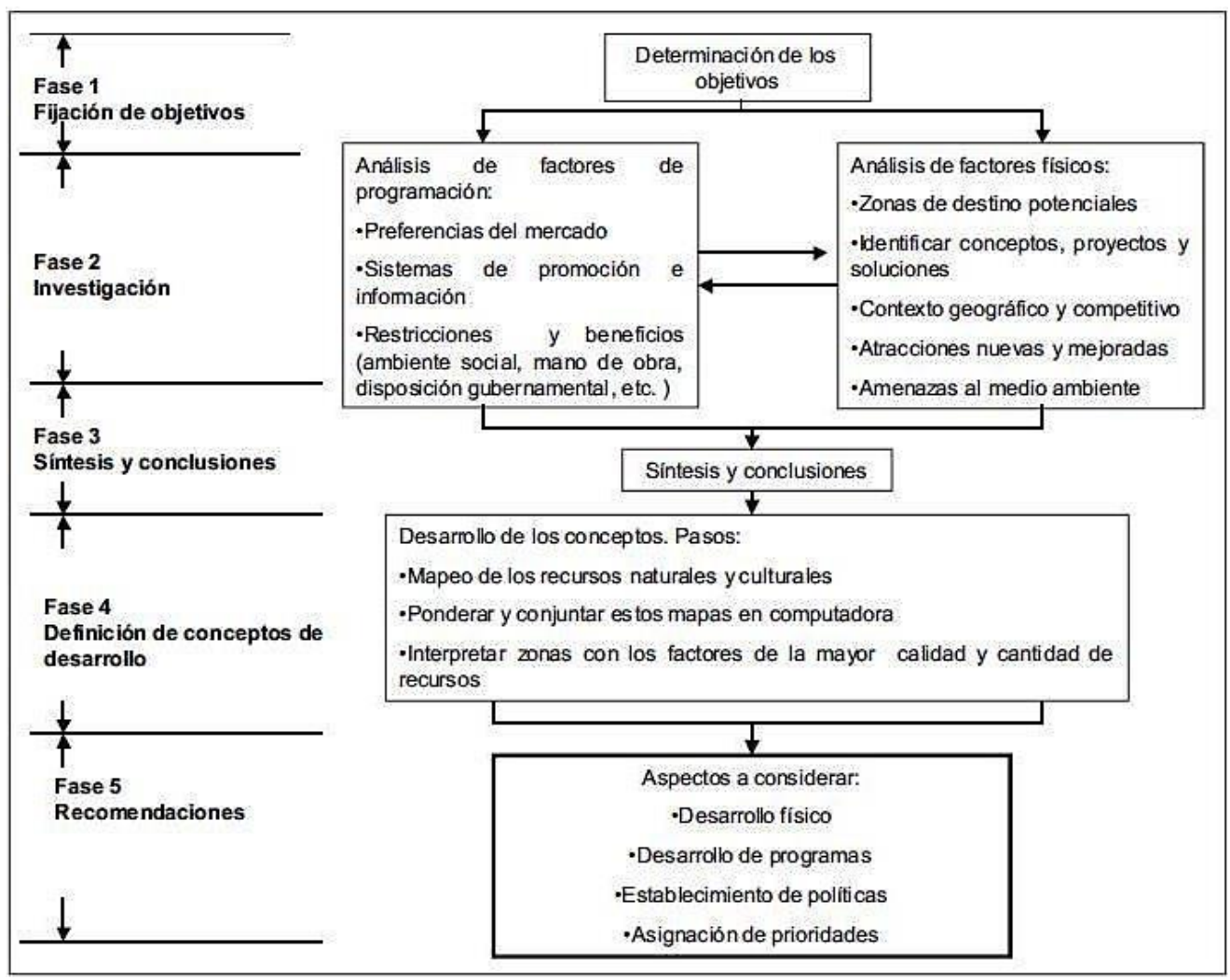

Fuente: Acerenza, 2006:63 y Osorio, 2006:303.

Cuadernos de Turismo, 35, (2015), 17-42 
Los anteriores enfoques metodológicos en la planificación turística no son excluyentes entre sí, en la práctica se combinan y complementan entre sí con el afán de trasladarse hacia una racionalidad sostenible.

En este trabajo se adopta como base el modelo regional de Gunn, no porque sea el ideal para alcanzar un turismo sostenible, sino porque integra el ordenamiento territorial y la geografía para destacar el potencial turístico como elemento clave y punto de partida en la toma de decisiones en la gestión del desarrollo local, que deberá complementarse con otros enfoques que integren variables económicas, políticas y de participación comunitaria.

\section{TENDENCIAS DE LA DEMANDA TURISTICA}

Bajo el punto de vista de la sostenibilidad el turismo de masas parece estar en crisis. María A. Cabeza (2001) afirma que hay indicios de una transformación de la demanda turística, que involucra cambios en el comportamiento y valores de los consumidores hacia la búsqueda de nuevos destinos turísticos, una mayor sensibilización hacia la problemática ambiental y la búsqueda de un valor añadido a través de la experiencia única.

En este contexto, aparece la modalidad de turismo alternativo o de bajo impacto, que se practica en lugares que permiten el contacto con la naturaleza a la vez que promueve una actitud de respeto por el ámbito sociocultural que la rodea. Entre los beneficios del turismo alterntivo se incluye la conservación y manejo sostenible de áreas naturales, la creación de empleos directos e indirectos y una mejora en el ingreso familiar de la población receptora (Schulte, 2001: 17-21). Bajo esta perspectiva el turismo concibe el espacio y su ambiente como un sistema complejo y sistémico, en donde los ejes económico, ambiental, social e institucional están en permanente interacción e interdependencia.

Desde nuestro punto de vista, el turismo de masas aún goza de popularidad y es incorrecto determinar una «crisis fatal» del modelo tradicional, además, a la par de los cambios en el comportamiento y valores de los consumidores, éstos exigen niveles de calidad cada vez más elevados que podrían estar fuera del alcance de algunas regiones y comunidades. Estas cuestiones obligan a renovar los modelos de gestión turística para compatibilizar las tendencias globales con la individualización del consumo, en correspondencia con las características de cada mercado receptor.

México por ejemplo, ha adoptado estrategias de difusión y planificación para el turismo alternativo hacia diversas zonas del territorio, especialmente aquellas con vegetación exuberante, climas templados y abundantes recursos hídricos que resultan atractivos para el turismo de aventura. (SECTUR: 2008). Bajo esa tendencia, el turismo parecería impensable en escenarios áridos, sin infraestructura de alojamiento o manutención de visitantes, sin sitios arqueológicos y con pueblos y comunidades aparentemente vacíos o poco poblados.

Sin embargo, diversas investigaciones y estudios locales y nacionales (COLSAN, 2008; Sánchez-Crispín, 2001; Vázquez y Benito, 2009; Eshragui et al., 2010) distinguen las zonas áridas y semiáridas como escenarios potenciales para la práctica de un turismo de naturaleza que contribuya al bienestar de la población involucrada, sin perder de vista su potencial económico.

En el país, estas zonas constituyen un poco más del cincuenta por ciento del territorio nacional y abarca los estados de Baja California, Baja California Sur, Sonora, Chihuahua, 
Coahuila, Sinaloa, Durango, Zacatecas, Tamaulipas, Aguascalientes, Colima, Guanajuato, Guerrero, Hidalgo, Jalisco, México, Michoacán, Nuevo León, Oaxaca, Puebla, Querétaro, Tlaxcala, Yucatán y San Luis Potosí (González, 2012).

\section{RECURSOS TURÍSTICOS Y SU CLASIFICACIÓN}

La Organización Mundial del Turismo (OMT) define los recursos turísticos como «todos los bienes y servicios que por intermedio de la actividad del hombre y de los medios con los que cuenta, hacen posible la actividad turística y satisfacen las necesidades de la demanda» (OMT, citado por Bote, 1990:123). En este sentido, todos los recursos naturales en un espacio determinado forman parte del patrimonio turístico en tanto muestren potencial para satisfacer necesidades turísticas, pero no se convertirá en recurso turístico sino hasta que, por intervención humana, se haga posible su utilización.

Para identificar y seleccionar los recursos naturales y socioculturales de un lugar, así como para valorar su potencial y posibilidades de uso y aprovechamiento se utilizan diferentes mecanismos de clasificación y evaluación. En este apartado se mencionan algunos de estos criterios metodológicos.

Se denomina inventario turístico al «catálogo de los lugares, objetos o acontecimientos de interés turístico de un área determinada» (Bote, 1990:143). Elaborar este listado es una tarea compleja y no hay una metodología que se adapte universalmente a las características de todas las áreas de estudio. Los métodos utilizan diversos criterios de categorización, algunos son clasificaciones sencillas con base a la naturaleza del recurso, otros se refieren a la funcionalidad del recurso, otros suman potencial e intervención humana para describir patrimonio turístico y algunas otras combinan dos o más criterios (Tabla 1).

En todos los casos, se distinguen técnicas de diagnóstico y evaluación para: identificar aquellos recursos con potencial turístico; seleccionar los que puedan desarrollarse en un plan a largo plazo; evaluar la vulnerabilidad y fortalezas de los recursos naturales y minimizar el impacto ambiental que el número de personas y las actividades realizadas provocarían en el espacio turístico, especialmente en aquellos con características ambientales frágiles.

Por su parte, la OEA elaboró una metodología con una clasificación por jerarquías y permite hasta cierto grado, valorar un elemento para considerarlo o no como recurso turístico. Las jerarquías son cuatro (Pitarch, 2009:451):

Jerarquía 3. Atractivo con rasgos excepcionales que motiva por sí solo una importante corriente de visitantes (actual o potencial).

Jerarquía 2. Atractivo excepcional en un país, que motiva corrientes de visitantes nacionales o extranjeros, solo o en conjunto con otros atractivos contiguos.

Jerarquía 1. Atractivo con algún rasgo importante que es capaz de interesar a visitantes de larga distancia que hayan acudido al lugar por otras razones

Jerarquía 0. Atractivo incapaz de atraer visitantes al nivel de los casos anteriores.

Aunque estas metodologías representan un referente en la clasificación y valoración de recursos turísticos, presentan puntos débiles importantes. Uno de ellos es la subjetividad en las opiniones de los turistas que se toman en cuenta para la jerarquización. Por otra parte, sólo consideran las características inherentes al recurso sin tomar en cuenta factores 
Tabla 1

CRITERIOS DE CATEGORIZACIÓN DE RECURSOS TURÍSTICOS

\begin{tabular}{|c|c|c|}
\hline $\begin{array}{c}\text { Criterio de } \\
\text { categorización }\end{array}$ & Autor & Elementos \\
\hline \multirow{2}{*}{$\begin{array}{l}\text { Según la } \\
\text { naturaleza de } \\
\text { los recursos }\end{array}$} & $\begin{array}{l}\text { Pierre Defert } \\
\text { (1972) }\end{array}$ & $\begin{array}{l}\text { a) Hidromo: Recursos relacionados con el agua } \\
\text { b) Litomo: Todo elemento construido por el hombre } \\
\text { c) Antropómo: relacionados con la estructura socio-económica } \\
\text { y de idiosincrasia del hombre } \\
\text { d) Phitomo elemento terrestre natural o modificado o no por el } \\
\text { hombre } \\
\text { e) Mnémome: recuerdo o memoria }\end{array}$ \\
\hline & $\begin{array}{l}\text { Gutiérrez } \\
\text { (1986) }\end{array}$ & $\begin{array}{l}\text { a) Regiones especiales: Parques, santuarios, áreas naturales } \\
\text { protegidas, reservas, etc. } \\
\text { b) Recursos biológicos: Fito geográficos y Zoográficos } \\
\text { c) Recursos físicos: Geomorfológicos e Hidrológicos }\end{array}$ \\
\hline $\begin{array}{l}\text { Según su } \\
\text { potencial } \\
\text { turístico }\end{array}$ & $\begin{array}{l}\text { Clawson } \\
\text { y Knetsch } \\
(1966)\end{array}$ & $\begin{array}{l}\text { a) Recursos orientados hacia el usuario: situados cercadel usuario } \\
\text { b) Recursos de tipo intermedio. Espacios de segunda residencia } \\
\text { c) Esparcimiento basado en el recurso. Áreas valiosas y frágiles } \\
\text { alejadas de la demanda }\end{array}$ \\
\hline \multirow{2}{*}{$\begin{array}{l}\text { Según su } \\
\text { calidad de } \\
\text { patrimonio } \\
\text { turístico }\end{array}$} & $\begin{array}{c}\text { Romero } \\
\text { (1986) }\end{array}$ & $\begin{array}{l}\text { a) Recurso turístico nacional: Todo elemento geomorfológico, } \\
\text { biofísico o la mezcla de ambos, cuyas características lo hagan } \\
\text { susceptible de ser visitado por turistas. } \\
\text { b) Recurso turístico cultural: Todo elemento creado por el } \\
\text { hombre que brinde atractivos capaces de interesar al visitante. }\end{array}$ \\
\hline & $\begin{array}{l}\text { Organización } \\
\text { de los Estados } \\
\text { Americanos } \\
(\text { OEA, 1990) }\end{array}$ & $\begin{array}{l}\text { a) Sitios naturales } \\
\text { b) Museos y manifestaciones culturales } \\
\text { c) Folklore } \\
\text { d) Relaciones técnicas, científicas o artísticas contemporáneas } \\
\text { e) Acontecimientos programados. }\end{array}$ \\
\hline \multirow{3}{*}{$\begin{array}{l}\text { Criterio } \\
\text { Mixto }\end{array}$} & $\begin{array}{l}\text { Corna } \\
\text { Pellegrini } \\
(1973)\end{array}$ & $\begin{array}{l}\text { a) Recursos originales: su función original es ajena al fenó- } \\
\text { meno turístico. } \\
\text { b) Recursos complementarios. Creados por el hombre para } \\
\text { aumentar la capacidad de atracción }\end{array}$ \\
\hline & $\begin{array}{c}\text { Bukart y } \\
\text { Medlik (1986) }\end{array}$ & $\begin{array}{l}\text { a) Básicos (Resource-based): La calidad del recurso es defi- } \\
\text { ciente para motivar el desplazamiento } \\
\text { b) Destinados a un uso específico (Resource user-oriented): La } \\
\text { accesibilidad es el factor de mayor valía }\end{array}$ \\
\hline & Gunn (1988) & $\begin{array}{l}\text { a) Tourist attractions. Aquellos que satisfacen la demanda de } \\
\text { un turismo itinerante } \\
\text { b) Destination attractions. Los que generan estancias turísticas }\end{array}$ \\
\hline
\end{tabular}

Fuente: Elaboración propia a partir de Arévalo (2008); Bote (1990); Gutiérrez et al. (1986); Leno (1991); Pitarch (2009) y Romero (1986). 
externos que pudiesen afectar su potencial turístico y finalmente, los esquemas valoran los tipos y número de recursos en un espacio determinado, pero no evalúa su capacidad de crear patrimonio o producto turístico.

En conclusión, no hay un método universalmente aceptado para la clasificación y valorización de recursos turísticos, pero se pueden recuperar factores básicos en cada una y adaptarlos a las circunstancias y características del territorio para conseguir una valoración aproximada y potencial de los recursos existentes. Estos elementos se tomaron en cuenta y permitieron identificar en la Zona Altiplano de San Luis Potosí los recursos naturales y socioculturales con potencial turístico.

\section{DIAGNÓSTICO DE LA BASE NATURAL Y SOCIOCULTURAL QUE FORMA EL ATRACTIVO TURÍSTICO DE UNA REGIÓN SEMIÁRIDA. EL CASO DEL ALTIPLANO POTOSINO}

En esta sección se realiza un diagnóstico del patrimonio turístico de la Zona Altiplano de San Luis Potosí. El objetivo no es realizar un inventario exhaustivo, sólo se han seleccionado aquellos recursos susceptibles de aprovechamiento turístico y de mayor relevancia, que pueden ser materia de una actividad turística planificada a largo plazo.

\subsection{Descripción de las dimensiones físicas, económicas, sociales e institucionales de la Zona Altiplano de San Luis Potosí}

En San Luis Potosí, la región árida y semiárida forma parte del Desierto Chihuahuense y se localiza en la Zona Altiplano. Ésta se ubica en la parte noroccidental del estado, entre los $22^{\circ} 16^{\prime}$ y $23^{\circ} 8^{\prime}$ de latitud norte y entre $\operatorname{los} 100^{\circ} 5^{\prime}$ y $101^{\circ} 10^{\prime}$ de longitud oeste; abarca 15 de los 58 municipios de la entidad y comprende un área aproximada de 29,119.80 Km²., que equivalen a 46.74\% de la superficie del Estado (SEDECO, 2013: 25).

En el Altiplano potosino se encuentra el grupo orográfico más importante del estado después de la Sierra Madre Oriental: al norte, las sierras de Charcas, de Catorce, de Guadalcázar, del Coro o Ypoa y San Pedro Naola; en el sur, las sierras del Peñón Blanco, Ahualulco y San Miguelito. En la parte occidental están las sierras del Sabino y de la Ballena, esta última en los límites con Zacatecas. La zona carece de ríos, la hidrografía del Altiplano está formada por un conjunto de cuencas endorreicas 5 , por corrientes de temporal, mantos subterráneos y algunos manantiales (Monroy y Calvillo, 2011).

El clima de la Zona Altiplano es seco-desértico-estepario, con una precipitación anual inferior a los $500 \mathrm{~mm}$. Los suelos que predominan son áridos. La fauna se compone de reptiles, mamíferos roedores, tlacuaches, zorrillos, lagartijas, culebras, víboras de cascabel, cenzontles, cuervos, halcones, zopilotes y águilas. La vegetación del lugar es de tipo xerofítico, predominan los matorrales desérticos como el cactus-mezquite, zacatal y encinar arbustivo. Por su ubicación geográfica, fusiona paisajes desérticos con

5 Se denomina cuenca cerrada o endorreica a aquélla que retiene el agua y no permite su cauce hacia los océanos, su única opción de salida es a través de evaporación o filtración. 
boscosos y combina la vegetación xerófila con bosque tropical caducifolio, de coníferas y de latifoliadas, lo que le proporciona una gran diversidad de relieves con atractivos naturales (INAFED, 2010)

El Altiplano potosino cuenta con tres áreas naturales protegidas (ANP), potenciadas como fuente de atractivos naturales: 1. Área Natural Protegida «Reserva Estatal del Paisaje Cultural Huiricuta, lugares sagrados y ruta histórico cultural del Pueblo Huichol», en los municipios de Catorce, Villa de la Paz, Matehuala, Charcas, Villa de Guadalupe y Villa de Ramos de San Luis Potosí; 2. La Reserva Estatal con características de Reserva de la Biósfera de Real de Guadalcázar, en el municipio del mismo nombre y 3. La Zona protectora y refugio de fauna silvestre «Sierra de Mojonera» en Vanegas (INE-RDSPNUD, 2001; POF, 2000; SEMARNAT-INE-CONAP, 2001:796).

En cuanto a las dimensiones económica y social, la población total del Altiplano en San Luis Potosí era de 350,927 habitantes en 2013. La zona es tradicionalmente minera y comercial, en ella se genera el $2.9 \%$ del valor bruto de la producción manufacturera del estado. Los principales subsectores manufactureros son: industria alimentaria, fabricación de productos a base de minerales no metálicos y fabricación de prendas de vestir (SEDECO, 2013: 25).

En materia de desarrollo humano, de acuerdo con datos del Programa de Naciones Unidas para el Desarrollo (PNUD, 2006), los municipios de la Zona Altiplano tienen un Índice de Desarrollo Humano promedio de .700 , que se traduce en un grado de desarrollo de 3 (Medio bajo). La población tiene un bajo nivel de ingreso; el 65\% de la población percibe de 1 a 2 salarios mínimos (INEGI, 2013a). Las altas tasas de marginación, la pobreza, la falta de oportunidades laborales y una fuerte cultura de migración hacen que varias comunidades y pueblos del Altiplano se perciban como lugares poco dinámicos, improductivos e inseguros (SEDESORE, 2010).

En cuanto a la dimensión institucional, destaca que la mayoría de los Ayuntamientos de la zona Altiplano, carecen de un departamento o comisión especializada en Ecología o Turismo y su normatividad ambiental o turística es nula o no actualizada, lo que implica que a nivel sectorial todavía rige el modelo unilateral de planificación que dictan las leyes federales y del estado (POF, 2009: 4).

\subsection{Recursos turísticos de la Zona Altiplano de San Luis Potosí. Metodología y resultados}

Aun cuando el Altiplano es una zona desértica, cuenta con características fisiográficas que ofrecen una amplia gama de paisajes y ambientes con potencial para la práctica de turismo de naturaleza, además de contar con elementos culturales que propician el turismo cultural y religioso. Para argumentar esta afirmación se realizó un catálogo de los recursos turísticos de los quince municipios que componen la Zona Altiplano.

El proceso se llevó a cabo en dos etapas: la primera consistió en una revisión documental de trabajos similares previos sobre la zona de estudio, informes gubernamentales e información institucional, para identificar el número, tipo y distribución de los recursos turísticos en la región. La segunda etapa consistió en trabajo de campo, en donde se verificaron y contrastaron los resultados de la información documental, además de recabar 
información oral con los pobladores, grupos ecologistas de la región y prestadores de servicios. ${ }^{6}$

Como resultado se identificaron cinco rutas que integran los atractivos naturales y socio culturales a lo largo del Altiplano Potosino: La Ruta 1, compuesta por los municipios de Vanegas y Catorce; la Ruta 2 la integran Matehuala, Villa de la Paz y Cedral; la Ruta 3 abarca Villa de Guadalupe, Charcas, Venado y Moctezuma; la Ruta 4 corresponde a Guadalcázar y en la Ruta 5 se encuentran Salinas, Villa de Ramos y Santo Domingo.

La información de las cinco rutas se agrupó y clasificó según criterios inspirados y adaptados de las metodologías propuestas por Romero (1986); Gutiérrez (1986); la OEA (citado en Bote, 1990) y Bote (1990) (Ver Tabla 1). Se eligieron estas clasificaciones porque corresponden a una visión geográfica en donde los elementos naturales y culturales se asocian en un espacio determinado con carácter permanente y a la vez proporcionan información sobre el potencial turístico de la región. Esta información constituye un punto de partida para la toma de decisiones en un proceso de planificación con acciones destinadas a la conservación del potencial turístico como una condición para el desarrollo turístico a largo plazo, según lo que argumenta Gunn y la economía ecológica.

Para elaborar el inventario en la Zona Altiplano de San Luis Potosí se redactó una ficha por cada recurso con los siguientes datos:

1) Ruta: Se indica el número de Ruta;

2) Tipo de recurso turístico: Distingue los recursos turísticos naturales y socioculturales;

3) Categoría: Ubica a los recursos turísticos en el grupo al que pertenecen por sus características. Los recursos naturales pueden ser físicos, regiones especiales, recursos biológicos; por su parte, los recursos socioculturales se dividen en manifestaciones culturales, manifestaciones técnicas o científicas y folklore.

4) Sub categoría: Sitúa el recurso turístico natural según se trate de un recurso geomorfológico, hidrológico, fitogeográfico o zoográfico. Los recursos socioculturales pueden ser parte de la arquitectura o infraestructura histórica o contemporánea; de la arquitectura religiosa; museos; plazas, jardines y cementerios; minería e industria; ciencia y tecnología; manifestaciones religiosas y creencias populares; ferias y festivales; gastronomía y artesanía.

5) Ubicación: Señala la localización del recurso

6) Denominación: Indica el nombre con el que se conoce al recurso turístico en orden alfabético

En total, el inventario para los 15 municipios de la Zona Altiplano consta de 270 atractivos turísticos, de los cuales 86 son naturales (51 físicos, 6 regiones especiales y 29 biológicos) y 184 socioculturales (100 manifestaciones culturales, 16 manifestaciones técnicas o científicas y 68 manifestaciones de folklor). Posteriormente se elaboró la cartografía y

6 Este trabajo se realizó durante los primeros meses del 2011 y 2012. Se utilizaron la observación directa a través de la experiencia como turista; el diario de campo para contrastar y registrar la información de los atractivos naturales, así como la aplicación de entrevistas semiestructuradas para recabar información de diversos actores involucrados. Esta información resultó de especial relevancia para la realización del FODA incluido en este documento. 
un análisis FODA para cada ruta para caracterizar y cada una de las áreas potenciales de desarrollo turístico en la región altiplano.

Ya que la estructura de esta publicación no permite presentar los resultados completos, como muestra se presenta en este documento los resultados cartográficos y de análisis FODA para los municipios de Catorce y Vanegas (Ruta 1) y Guadalcázar (Ruta 4), estas rutas y sus municipios fueron seleccionados una vez que se identificaron con la metodología ya descrita, como lugares con similar potencial y riqueza en sus atractivos turísticos naturales y culturales, pero con estrategias de planificación opuestas.

\subsection{Comparativa Guadalcázar y Catorce}

En el municipio de Catorce se encuentra el pueblo de Real de Catorce, una localidad minera catalogada como «pueblo mágico» ${ }^{7}$ y que constituye el referente turístico principal de la región Altiplano. El lugar cuenta con proyección nacional e internacional y con un buen financiamiento por parte del gobierno estatal.

La planificación turística en el lugar es reciente y según el gobierno estatal, ésta pretende enriquecer y acrecentar el atractivo del lugar a la vez que regula y ordena el crecimiento turístico para corregir prácticas ilegales relacionadas con el interés en el peyote, combatir la estacionalidad de las visitas y elevar la derrama económica (POF, 2009).

En los últimos años, debido al cambio en el perfil del turista, a la promoción institucional y popular de la Zona Altiplano y a la infraestructura en comunicaciones que actualmente conecta a las cabeceras municipales (http://www.turismoslp.com.mx/; Vázquez et al., 2008), surgen nuevos sitios de interés en el Altiplano, entre los que destaca Guadalcázar. Este municipio es considerado el centro principal de cactáceas en el estado; cuenta con un Área Natural Protegida (ANP) caracterizada como Reserva de la Biósfera; posee una interesante diversidad de fauna; sus características físico-geográficas confieren un gran atractivo para los interesados en actividades de naturaleza y de aventura; y su arquitectura, plazas y festividades constituyen un patrimonio cultural con alto valor histórico (http:// www.turismoslp.com.mx/).

Sin embargo, del resultado de trabajo de campo, se verificó que las prácticas de turismo de naturaleza son impulsadas por los propios pobladores del municipio en forma espontánea y no planificada; a esto se agrega el poco interés y conciencia de la población por su riqueza natural y cultural; la escasa inversión pública y privada en proyectos de turismo, así como una nula planeación turística.

En conjunto, esas circunstancias han hecho que el patrimonio turístico en Guadalcázar se encuentre en un estado general de deterioro y degradación que disminuye sus oportunidades como detonador del desarrollo turístico y socioeconómico de la región.

En las Figuras 2 y 3 se muestra la distribución del patrimonio turístico de las rutas 1 y 4 , respectivamente.

7 Un Pueblo Mágico es, según la Secretaría de Turismo en México, un lugar que tiene atributos simbólicos, leyendas, historia, hechos trascendentes y cotidianidad que se cataloga como «magia», cuyo reconocimiento significa una gran oportunidad para el aprovechamiento turístico. 


\section{Figura 2 \\ INVENTARIO DE RECURSOS TURÍSTICOS DE LAS RUTA 1 (CATORCE Y VANEGAS) DE LA ZONA ALTIPLANO, S.L.P}
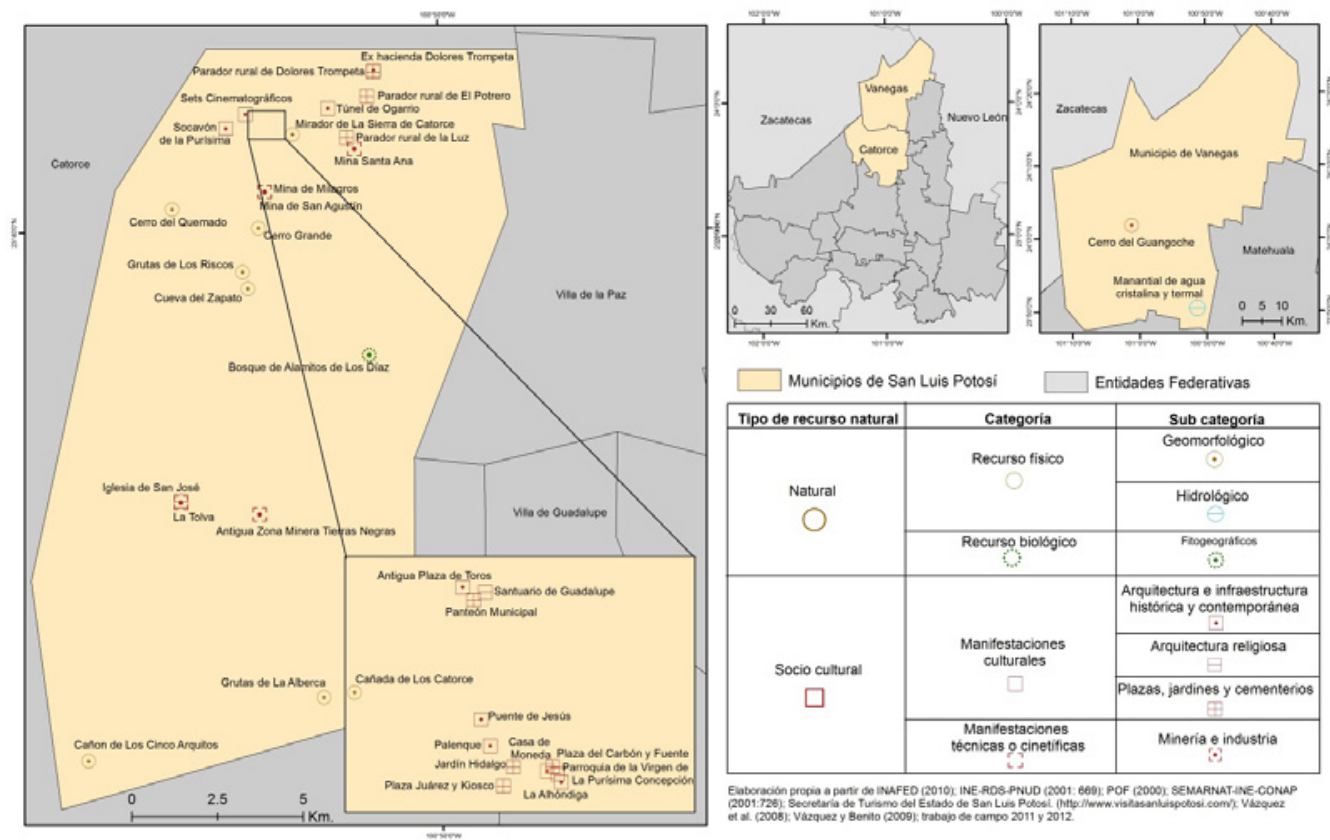

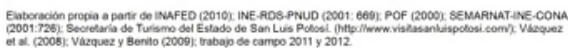

Se aprecia en la Figura 1 que el patrimonio turístico de la Ruta 1 reúne 32 atractivos turísticos, de los cuales 10 son naturales (9 físicos y 1 biológico) y 22 son socioculturales (18 manifestaciones culturales y 4 manifestaciones técnicas o científicas). La mayor parte de ese patrimonio se concentra al norte del municipio de Catorce.

En la Figura 2 se observa que la mayor parte del patrimonio turístico de la Ruta 4 se encuentra al sur del municipio de Guadalcázar, en su cabecera municipal y alrededores. Éste se compone de 25 atractivos turísticos; 12 son naturales (11 físicos y 1 biológico) y 13 socioculturales (10 manifestaciones culturales y 2 manifestaciones técnicas o científicas).

Así, se verifica que tanto Guadalcázar como Catorce cuentan con un número significativo de recursos naturales y socioculturales con buenas expectativas para el desarrollo turístico en la región. Sin embargo, en la práctica se observa una disociación entre el potencial de estos municipios y las estrategias de desarrollo turístico impulsadas por el gobierno estatal y municipal.

La situación trasciende hacia el resto de los municipios de la Zona Altiplano debido a una excesiva simplificación de las políticas y planificación del desarrollo turístico en la región, ya que la mayor parte de los procesos de gestión se concentran en Real de Catorce. Al respecto se argumentará en el siguiente apartado. 


\section{Figura 3 \\ INVENTARIO DE RECURSOS TURÍSTICOS DE LA RUTA 4 (GUADALCÁZAR) DE LA ZONA ALTIPLANO, S.L.P}
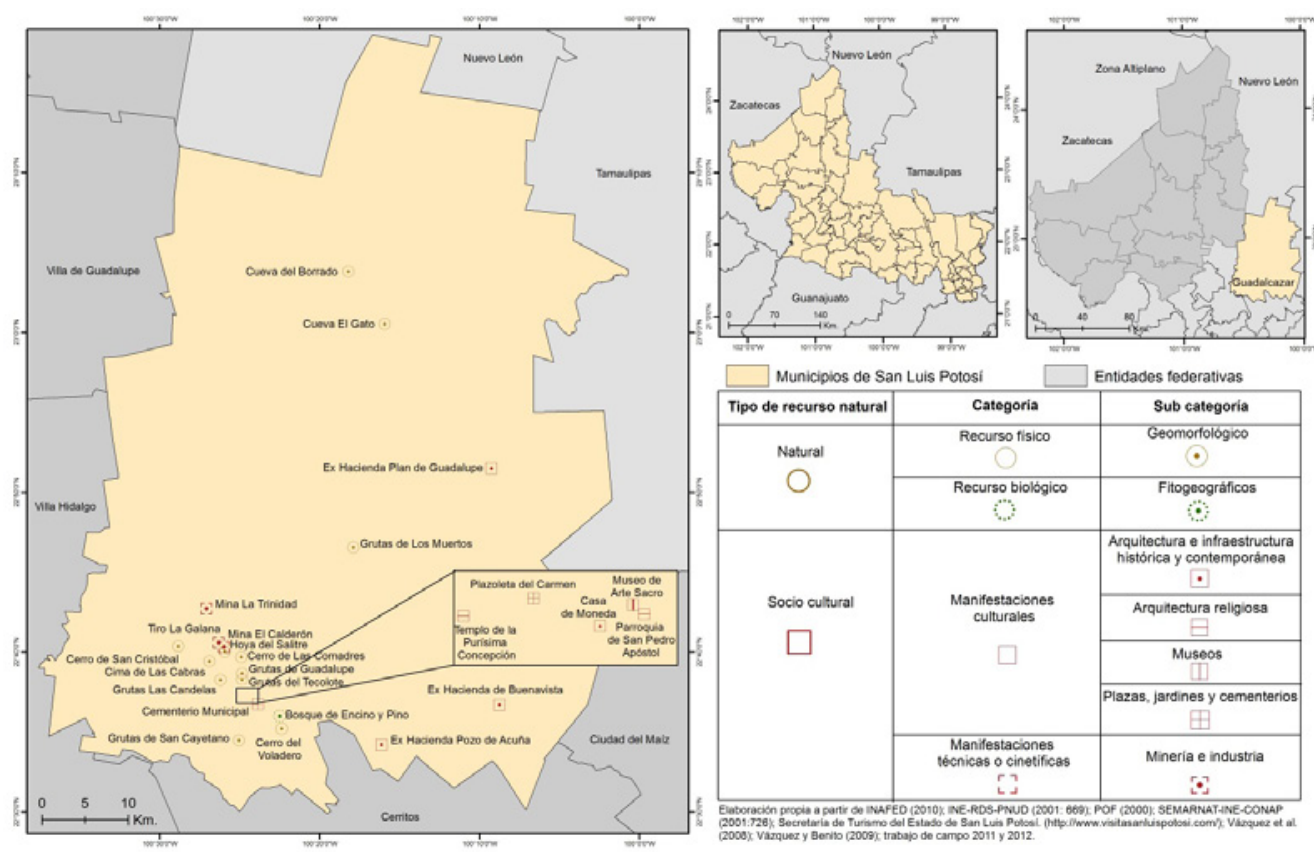

\section{INSTRUMENTOS DE PLANIFICACIÓN DEL DESARROLLO TURÍSTICO EN LA ZONA ALTIPLANO DE SAN LUIS POTOSÍ}

En San Luis Potosí, el proceso de planeación está sujeto al Plan Estatal de Desarrollo (PED), a partir del cual se elaboran los planes municipales, programas regionales, sectoriales, especiales, institucionales y en general, cualquier instrumento de planeación del desarrollo estatal (COPLADE, 2010).

El PED 2010-2015 inserta el sector Turismo en el Eje 2, denominado Economía Competitiva y Generadora de Empleos y define tres objetivos para el sector: 1) Fortalecer esquemas que permitan posicionar al estado como destino turístico; 2) Fomentar y desarrollar los atractivos turísticos del estado con la finalidad de incrementar el número de turistas y visitantes y 3) Incrementar la competitividad de prestadores de servicios turísticos en el estado.

La planificación turística para San Luis Potosí se concentra en el Programa Sectorial de Turismo 2010-2015, que identifica como uno de los retos y prioridades a mediano plazo «el aprovechamiento sostenible de recursos naturales, sociales y culturales de acuerdo a las nuevas condiciones y características que se encuentran cada vez más entre turistas y operadores de viajes...» (COPLADE, 2010:42). 
A su vez, la estrategia de desarrollo turístico para la Zona Altiplano se concentra en el Programa Regional de Desarrollo Turístico de los Pueblos Mineros del Altiplano Potosino (PREDETALP) (POF, 2009), una política relativamente joven, pues entró en vigor en febrero de 2009. Este programa comprende sólo siete de los 15 municipios del Altiplano (Matehuala, Villa de Guadalupe, Guadalcázar, Charcas, Salinas, Catorce y Villa de la Paz) e identifica 103 recursos turísticos que integra en 6 subregiones turísticas, 20 rutas y 12 circuitos.

La estrategia de desarrollo del PREDETALP busca «planear el desarrollo turístico sostenible del Altiplano Potosino, con base en estrategias y acciones que fomenten su oferta, mejoren los servicios, le doten de infraestructura y equipamiento, lo promocionen y lo comercialicen, aprovechando los recursos y herramientas de los diferentes organismos y niveles de gobierno» (POF, 2009: 16). En general, sus objetivos, lineamientos y estrategias se enfocan en fomentar, promocionar y comercializar la oferta turística de la región aprovechando los recursos existentes, mejorar los servicios, dotar de infraestructura y equipamiento para prolongar la estadía y el gasto de los turistas con el objetivo de convertir al Altiplano en un destino con calidad frente a los principales mercados del país (POF, 2009).

A pesar de estos planteamientos, los objetivos y estrategias del PREDETALP están alineados a los ejes y objetivos del Plan Nacional de Desarrollo 2007-2012, del Plan Estatal de Desarrollo 2010-2015, del Plan Nacional de Turismo (PNT) y del Programa Estatal de Turismo (PET) (POF, 2009:4). El Gobierno de San Luis Potosí argumenta que esta alineación se realiza «a fin de coadyuvar con las políticas y programas de los tres ámbitos de gobierno para contribuir en la región a fomentar el empleo, el desarrollo socioeconómico y los procesos productivos, a la vez que protege los recursos naturales existentes» (POF, 2009: 5).

La verdad es que debido al esquema centralista de planeación en México, las estrategias, acciones y proyectos del PREDETALP están supeditados a los lineamientos establecidos por el marco de la Federación y del estado de San Luis Potosí y no principalmente a las características físicas y comunitarias de la Zona Altiplano.

A cuatro años de la implementación y vigencia del PREDETALP son varios los problemas que se identifican. Uno de ellos es la banalización que se hace de la palabra «sostenibilidad», ya que los objetivos planteados no fueron concebidos como instrumentos de desarrollo sostenible o en razón de criterios ambientales y en cambio, predomina un carácter político y económico. Por otra parte, no existe una consistencia metodológica que vincule entre sí los objetivos, estrategias y acciones, es decir, se presenta el qué, pero no se explica cómo se desarrollarán las acciones para sinergizar el turismo y la sostenibilidad.

La situación se agrava cuando se constata que la mayoría de los municipios del Altiplano carece de normatividad ambiental y las actividades turísticas y sus efectos suelen encargarse a los departamentos de limpia y ecología. Esto provoca que en la práctica la coordinación entre los ámbitos de gobierno sea complicada y que los espacios turísticos se limiten a ser un simple soporte para la oferta y demanda, en donde se asume que el bienestar y el aumento de calidad de vida de la población es un logro secundario derivado de la dinámica del mercado.

Otra falla evidente es, que a pesar de que se reconoce la vocación del territorio hacia los atractivos ambientales y culturales en toda la Zona Altiplano, la planificación diseñada 
para la región es compacta y homogénea; es decir, se desestima la caracterización de las unidades territoriales específicas, no existen estrategias diversificadas hacia cada segmento turístico (culturales, religiosos, de aventura, ecoturísticos) ni hacia las particularidades de los grupos interesados (familias, estudiantes, adultos mayores, excursionistas). De hecho, el segmento de mercado que intenta atraer la actual estrategia turística del Altiplano son visitantes con capacidad adquisitiva que generen un fuerte gasto en la región, pero la práctica demuestra que, aunque se reciben visitantes de alto poder adquisitivo e internacionales, también hay un gran segmento de visitantes que desde la perspectiva gubernamental se consideran como no representativos en cuanto a derrama económica, pero con presencia constante. Esto refuerza nuestro argumento sobre la necesidad de que la planificación gubernamental tome en cuenta las particularidades de las comunidades y de los visitantes para diseñar estrategias que maximicen los beneficios económicos, sociales y ambientales en cada localidad.

Bajo esta perspectiva y con los datos recabados en la investigación documental, el trabajo de campo, la observación a través de la experiencia como visitante y las entrevistas con prestadores de servicios, usuarios, población y personal de la Secretaría de Turismo, se realizó un análisis de las Fortalezas, Oportunidades, Debilidades y Amenazas (FODA) de la actividad turística actual en cada una de las rutas del Altiplano potosino, con el objetivo de realizar una propuesta inicial de aprovechamiento para la región, tomando como punto de partida la información del patrimonio turístico.

Como muestra se presenta en este documento los resultados de análisis FODA y la propuesta de aprovechamiento para los municipios de Catorce y Vanegas (Ruta 1) y Guadalcázar (Ruta 4), (Tabla 2).

\section{PROPUESTA DE APROVECHAMIENTO TURÍSTICO PARA LAS RUTAS 1 Y 4 DE LA ZONA ALTIPLANO DE SAN LUIS POTOSÍ. METODOLOGÍA Y RESULTADOS}

Una vez que se evaluaron los instrumentos de planificación turística para la Zona Altiplano y que se identificó, analizó e ilustró la distribución de los atractivos turísticos naturales y socioculturales de cada municipio, se hizo una propuesta inicial de aprovechamiento turístico con base el potencial de cada ruta y a un análisis de oferta-demanda.

El primer paso fue identificar los aspectos del Altiplano potosino que atraen mayor número de visitantes. Se revisaron los diagnósticos del perfil del visitante que realiza la Secretaría de Turismo del Estado de San Luis Potosí (SecturSLP) (2010, 2012a y 2012b) sobre los motivos que provocaron el desplazamiento del visitante con fines turísticos a la Zona Altiplano en el invierno de 2010, verano y Semana Santa de 2012. Esto nos permitió identificar el tipo de necesidades que busca satisfacer el visitante actual del Altiplano potosino, entre las que destacan las culturales $(15 \%)$, religiosas $(11.4 \%)$ y de naturaleza $(11.7 \%)^{9}$

8 Se tomaron en cuenta tres de los periodos vacacionales más importantes en un año. A la fecha de realización de este documento sólo se contaba con información del 2010 para el periodo invernal.

9 En el análisis estadístico de SECTUR se toman en cuenta las siguientes variables: Visita a familiares; cultural; negocios; religiosos; turismo de aventura; ecoturismo; romance; naturaleza; gastronómico; compra de 
Tabla 2

ANÁLISIS FODA DE LA ACTIVIDAD TURÍSTICA EN LAS RUTAS 1 (CATORCE Y VANEGAS) y 4 (GUADALCÁZAR) DEL ALTIPLANO POTOSINO

\begin{tabular}{|c|c|c|c|}
\hline RUTA & ELEMENTO & UBICACIÓN & DESCRIPCIÓN \\
\hline \multirow[t]{4}{*}{1} & \multirow[t]{2}{*}{ Fortalezas } & $\begin{array}{l}\text { Real de } \\
\text { Catorce }\end{array}$ & $\begin{array}{l}\text { - Aún es la referencia turística nacional e internacional más conocida de la } \\
\text { Zona Altiplano, gracias a lo cual tiene una gran promoción como destino turís- } \\
\text { tico } \\
\text { - Debido a este auge turístico la infraestructura turística ha ido en aumento } \\
\text { - Tiene una amplia oferta para realizar todas las actividades del turismo de } \\
\text { naturaleza (aventura, ecoturismo, rural, étnico, religioso, cultural) } \\
\text { - La población se ha involucrado en el desarrollo turístico, lo cual se refleja en } \\
\text { grupos como «Los Caballerangos del Real», «Los Catorce Reales» y los guías }\end{array}$ \\
\hline & & Vanegas & $\begin{array}{l}\text { - Es el lugar con el único recurso hidráulico de la ruta, lo cual resulta un } \\
\text { atractivo para el turista que busca un oasis en el desierto } \\
\text { - Consta de una zona protectora y refugio de fauna silvestre que se encuentra } \\
\text { bien conservada y constituye un atractivo natural en potencia }\end{array}$ \\
\hline & \multirow[t]{2}{*}{ Oportunidades } & $\begin{array}{l}\text { Real de } \\
\text { Catorce }\end{array}$ & $\begin{array}{l}\text { - Los hoteles y restaurantes pueden elevar su nivel de calidad para generar } \\
\text { mayor gasto en sectores turísticos de altos ingresos, a fin de contrarrestar el } \\
\text { poco gasto que generan grupos juveniles o estudiantiles } \\
\text { - Cuenta con productos turísticos que pueden romper con la estacionalidad } \\
\text { turística y promover un aumento en el interés y en la estadía }\end{array}$ \\
\hline & & Vanegas & $\begin{array}{l}\text { - Consta de recursos geomorfológicos, hidrológicos y regiones especiales } \\
\text { que gracias a su valor turístico en potencia puede integrarse en recorridos para } \\
\text { incrementar su atractivo y promoción }\end{array}$ \\
\hline & \multirow[t]{2}{*}{ Debilidades } & $\begin{array}{l}\text { Real de } \\
\text { Catorce }\end{array}$ & $\begin{array}{l}\text { - Su crecimiento turístico ha sido espontáneo y la planificación ha sido mínima } \\
\text { por el ámbito estatal y municipal durante mucho tiempo. } \\
\text { - Existen grupos de jóvenes, estudiantes y otros de bajo perfil económico } \\
\text { que generan poco gasto al no utilizar los servicios de hospedaje y restaurantes } \\
\text { establecidos } \\
\text { - Debido a los bajos ingresos de la población y de la poca sensibilización, } \\
\text { proporcionan información a los visitantes sobre el consumo del peyote a cambio } \\
\text { de una remuneración económica } \\
\text { - Aún es un destino para fin de semana y periodos vacacionales que coinciden } \\
\text { con festividades religiosas, que provocan ingresos de temporada. } \\
\text { - La pobreza en algunos segmentos de la población, aunado a la poca sensibi- } \\
\text { lización ambiental provoca la venta clandestina de peyote }\end{array}$ \\
\hline & & Vanegas & $\begin{array}{l}\text { - Sólo cuenta con dos establecimientos de hospedaje de clase económica, lo } \\
\text { que provoca que el visitante prefiera hospedarse en Real de Catorce }\end{array}$ \\
\hline & \multirow[t]{2}{*}{ Amenazas } & $\begin{array}{l}\text { Real de } \\
\text { Catorce }\end{array}$ & $\begin{array}{l}\text { - Hay grupos específicos de jóvenes y extranjeros que se ven atraídos por el } \\
\text { lugar por prácticas ilegales relacionadas al consumo del peyote } \\
\text { - Evidencia de contaminación por desechos mineros }\end{array}$ \\
\hline & & Vanegas & $\begin{array}{l}\text { - La promoción turística centralizada en Real de Catorce opaca la curiosidad } \\
\text { del turista por los atractivos naturales del lugar }\end{array}$ \\
\hline
\end{tabular}




\begin{tabular}{|c|c|c|c|}
\hline RUTA & ELEMENTO & UBICACIÓN & DESCRIPCIÓN \\
\hline \multirow[t]{2}{*}{4} & Fortalezas & Guadalcázar & $\begin{array}{l}\text { - Cuenta con una gran oferta de atractivos naturales, culturales y religiosos } \\
\text { bien conservados para diversos tipos de práctica turística. } \\
\text { - La mayoría de los atractivos naturales cuenta con equipamiento adecuado } \\
\text { para la práctica de actividades de aventura y ecoturísticas } \\
\text { - Cuenta con línea propia de transporte público con salidas frecuentes } \\
\text { - Es de los pocos municipios del Altiplano que cuenta con un museo con } \\
\text { patrimonio cultural local y con un fideicomiso (Museo de Arte Sacro) } \\
\text { - Solidaridad y sentido de pertenencia de sus pobladores hacia el patrimonio } \\
\text { natural y cultural } \\
\text { - Los responsables directos de las rutas y circuitos están capacitados y reco- } \\
\text { nocidos a nivel estatal y municipal para fomentar las actividades turísticas }\end{array}$ \\
\hline & Oportunidades & Guadalcázar & $\begin{array}{l}\text { - Por ubicarse en los límites entre el Altiplano y la zona Media, fusiona paisa- } \\
\text { jes desérticos con montañosos que se pueden potenciar para diversas actividades } \\
\text { ecoturísticas } \\
\text { - Su amplia oferta turística lo hacen un destino con potencial para el turismo } \\
\text { de naturaleza } \\
\text { - Sus recursos turísticos naturales de gran belleza pueden aprovecharse para } \\
\text { provocar mayor estadía y mayor gasto } \\
\text { - La mejora en la infraestructura turística en los campamentos puede provocar } \\
\text { mayor estadía y comodidad en los visitantes } \\
\text { - La vida que cobra el municipio durante las festividades decembrinas pueden } \\
\text { exaltarse para provocar interés turístico }\end{array}$ \\
\hline & Debilidades & Guadalcázar & $\begin{array}{l}\text { - La cabecera municipal es poco dinámica la mayor parte del año, lo que } \\
\text { proyecta una imagen pasiva del municipio } \\
\text { - Poca infraestructura turística y de baja calidad que afectan la estadía del visitante } \\
\text { - No existe promoción o información por parte de las autoridades municipales } \\
\text { - La promoción de los atractivos naturales ha sido espontánea con mínima } \\
\text { planificación por parte de las autoridades municipales } \\
\text { - Algunos intentos por promover la participación de la población en los servi- } \\
\text { cios turísticos han fracasado, ya que aún no consideran al turismo como fuente } \\
\text { principal de ingresos } \\
\text { - Conflictos entre la población, que consideran que los beneficios del turismo } \\
\text { se concentran en manos de un par de personas } \\
\text { - No hay evidencia de que el turismo de aventura se desarrolle con estudios } \\
\text { previos de mercado } \\
\text { - La Comunidad de Charco Cercado es tristemente famosa por el comercio } \\
\text { ilegal de flora y fauna silvestre }\end{array}$ \\
\hline & Amenazas & Guadalcázar & $\begin{array}{l}\text { - Fuerte tradición migrante entre sus pobladores que provocan abandono en la } \\
\text { cabecera municipal } \\
\text { - Escaso conocimiento y compromiso ambiental por parte del visitante que } \\
\text { puede dañar los recursos naturales ya sea por depredación o destrozo } \\
\text { - Deterioro natural y gradual de los atractivos naturales } \\
\text { - Exclusión de la población si se promueve la inversión de proyectos foráneos } \\
\text { - Actitud permisiva de las autoridades ante prácticas ilegales de comercio de } \\
\text { flora y fauna } \\
\text { - Evidencia de contaminación por desechos mineros }\end{array}$ \\
\hline
\end{tabular}

Elaboración propia a partir de POF (2009) y trabajo de campo 2011-2012.

Cuadernos de Turismo, 35, (2015), 17-42 
Estos datos se contrastaron con el tipo y número de recursos turísticos de cada ruta para verificar la relación y coherencia entre la oferta y la demanda turística. Posteriormente se revisaron las propuestas oficiales de aprovechamiento turístico en los instrumentos de planificación vigentes y en la página web de SecturSLP.

En el caso de las rutas 1 y 4 que en este documento se han ejemplificado, se identificaron un total de 95 atractivos turísticos, de los cuales 36 son naturales (29 físicos, 3 regiones especiales y 4 biológicos) y 59 socioculturales (29 manifestaciones culturales, 10 manifestaciones técnicas o científicas y 20 manifestaciones de folklor). En estas rutas, el PREDETLAP diseña 13 rutas y 5 circuitos para Catorce y Guadalcázar, con actividades de turismo de aventura, cultura, religioso, naturaleza, rural y ecoturismo, aunque no se describen cuáles son las actividades específicas que se proponen para cada categoría. Por su parte, Sectur SLP propone 6 actividades de aventura y 1 cultural para ambos municipios.

A partir de la información institucional y los hallazgos de campo en esta investigación, se realizó una propuesta de aprovechamiento turístico para la Zona Altiplano que toma en cuenta el tipo y distribución de los recursos, así como la vocación turística del territorio. Se integraron propuestas de turismo de naturaleza ${ }^{10}$ con actividades rurales religiosas, gastronómicas y artesanales, entre ellas: la convivencia con los contadores de leyendas; la visita de los lugares sagrados de la etnia Huichol y de los pueblos ligados a un pasado de esplendor minero como Real de Catorce; los festejos de las fiestas patronales que incluyen eventos culturales, danzas, jaripeos, verbenas, competencias deportivas, etc.; la exploración y visita a las antiguas haciendas mineras o restos de minas y a los sets cinematográficos; también se proponen actividades ecoturísticas de bajo impacto como senderismo interpretativo, ciclismo de montaña, jeeps o cabalgata; campamentos ecoturísticos y actividades de aventura como rappel o escalada. (Tabla 3).

\section{CONCLUSIONES}

En cuanto a los instrumentos gubernamentales, el PREDETLAP representa un avance significativo para la planificación turística en la Zona Altiplano. Uno de sus aciertos es la integración articulada -aunque no integral- en recorridos y circuitos de municipios y localidades que anteriormente se consideraban con mínimo o nulo valor turístico, aunque es evidente que no hay estrategias encaminadas a resaltar su atractivo turístico individual; por ejemplo, no existe una estrategia diseñada y estructurada de producción y comercialización de productos gastronómicos y artesanales.

Las tradiciones, cultura y fiestas religiosas son actividades potenciadas en la planificación actual para provocar el desplazamiento del turista en épocas específicas del año, aunque esto posiciona al Altiplano como un destino estacional y sus habitantes consideran

artesanías; salud; deportivo y otros. En los tres periodos destaca como primer motivo de viaje a la Zona Altiplano la «visita a familiares». Para efectos del tema de análisis de este documento se tomaron en cuenta únicamente aquellos motivos relacionados con la práctica turística.

10 La Secretaría de Turismo define al Turismo de Naturaleza como: «Los viajes que tienen como fin realizar actividades recreativas en contacto directo con la naturaleza y las expresiones culturales que le envuelven con una actitud y compromiso de conocer, respetar, disfrutar y participar en la conservación de los recursos naturales y culturales». El Turismo de Naturaleza es dividido en tres grandes segmentos, cada uno compuesto por diversas actividades: Ecoturismo, Turismo de Aventura y Turismo Rural (SECTUR, 2008) 
Tabla 3

ACTIVIDADES TURÍSTICAS SUGERIDAS PARA LA RUTA 1 Y 4 DEL ALTIPLANO POTOSINO

\begin{tabular}{|c|c|c|c|}
\hline Ruta & Ubicación & Denominación & Actividades sugeridas \\
\hline \multirow[t]{6}{*}{1} & Catorce & $\begin{array}{l}\text { Pueblo Real de Catorce } \\
\text { Sets Cinematográficos } \\
\text { Cerro del Quemado } \\
\text { Cañada de los Catorce } \\
\text { Socavón de la Purísima }\end{array}$ & \multirow[t]{2}{*}{$\begin{array}{l}\text { - Cabalgata } \\
\text { - Safari } \\
\text { - Cabalgata } \\
\text { - Senderismo }\end{array}$} \\
\hline & Vanegas & $\begin{array}{l}\text { Cerro de Guanache } \\
\text { Grutas los Riscos } \\
\end{array}$ & \\
\hline & \multirow[t]{2}{*}{ Catorce } & $\begin{array}{l}\text { Antigua Alhóndiga } \\
\text { Casa de Moneda } \\
\text { Palenque } \\
\text { Parroquia de la Virgen de la Purísima } \\
\text { Concepción } \\
\text { Capilla de la Consolación } \\
\text { Ruta sagrada de Wirikuta }\end{array}$ & - Turismo cultural \\
\hline & & $\begin{array}{l}\text { Actividades de Semana Santa } \\
\text { Fiesta patronal de San Francisco de Asís }\end{array}$ & - Turismo religioso \\
\hline & Catorce & San Antonio de Coronados & - Turismo rural y de salud \\
\hline & Vanegas & Manantial de agua cristalina y termal & - lurismo rural y de salud \\
\hline \multirow[t]{3}{*}{4} & \multirow[t]{3}{*}{ Guadalcázar } & $\begin{array}{l}\text { El Realejo } \\
\text { Cerro de Las Comadres } \\
\text { Cerro de Los Arcos } \\
\text { Cerro de San Cristóbal } \\
\text { Cueva El Gato } \\
\text { El espinazo del diablo } \\
\text { Hoya del Salitre } \\
\text { Grutas Las Candelas } \\
\end{array}$ & $\begin{array}{l}\text { - Rápel } \\
\text { - Escalada } \\
\text { - Cabalgata } \\
\text { - Espeleología } \\
\text { - Ciclismo de montaña } \\
\text { - Campismo } \\
\text { - Senderismo }\end{array}$ \\
\hline & & $\begin{array}{l}\text { Parroquia de San Pedro Apóstol } \\
\text { Templo de la Purísima Concepción } \\
\text { Museo de Arte Sacro } \\
\text { Ex Hacienda Plan de Guadalupe }\end{array}$ & - Turismo cultural \\
\hline & & Fiesta patronal de la Purísima Concepción & - Turismo religioso \\
\hline
\end{tabular}

Fuente: Elaboración propia a partir de trabajo de campo 2011 y 2012; inventario de patrimonio turístico y análisis FODA de cada una de las rutas de la Zona Altiplano de San Luis Potosí

la actividad como algo de temporada que no constituye su principal fuente de ingresos, lo que puede impedir un crecimiento constante y regular. Por otra parte, la infraestructura turística ha crecido en lugares estratégicos Real de Catorce, pero la oferta hotelera en la mayoría de los municipios aún es escasa y de baja calidad y las instalaciones no son adecuadas para la práctica del turismo de aventura, sin mencionar que la capacitación del personal resulta muy general y no incluyen especialización en técnica y manejo de equipo 
para actividades de aventura y ecoturísticas, que son las actividades recomendadas para la región. Esto demuestra una estrategia de desarrollo focalizada.

En este documento se ejemplificó a través de un inventario estrictamente territorial de las rutas con similar y mayor potencial turístico, que el Altiplano potosino cuenta con una buena oferta de recursos naturales y socioculturales con atractivo turístico y valor único en el segmento de zonas áridas y semiáridas, que le otorgan un alto potencial para el desarrollo de la región. En contraste, tal como se verificó en el análisis de los instrumentos de gestión para la Zona Altiplano, la planificación turística es compacta y poco diversificada; no toma en cuenta las particularidades de cada parte del territorio, de forma que la actividad turística y sus beneficios se concentra sólo en algunas partes de la región $\mathrm{y}$ en actividades de aventura.

Esto podría provocar a largo plazo una sobrecarga de visitantes y el incremento en los riesgos ambientales, pues aunque la oferta turística del Altiplano atrae a un tipo de turista que busca contacto con la naturaleza, esto no es garantía de que el visitante sea informado, comprometido y con cultura ecológica y sostenible; lo que puede provocar prácticas como el comercio ilegal de flora y fauna silvestre, un inadecuado manejo de desechos y daños premeditados a los recursos naturales, que a corto y mediano plazo disminuyen el interés en los turistas y por ende, menores visitas e ingresos.

El inventario turístico realizado en el marco de esta investigación y que aquí se ejemplifica a través de dos rutas, constituye una primera aproximación a las herramientas básicas para la toma de decisiones. Éste deberá integrarse a una estrategia coordinada de desarrollo que dimensione las particularidades físicas, sociales, económicas y políticas en la región; que contemple un análisis de los impactos; la generación de una infraestructura y oferta turística básica y de calidad; la creación de instrumentos de regulación, colaboración y coordinación entre los tres ámbitos de gobierno, sector privado y sociedad civil, y el diseño de instrumentos financieros y esquemas de inversión que permitan capitalizar en forma sostenible los productos turísticos y los recursos humanos de la región.

\section{BIBLIOGRAFÍA}

ACERENZA, M. (2006): Política turística y planificación del turismo. Editorial Trillas, México.

ACERENZA, M. (2007): Desarrollo Sostenible y Gestión del Turismo. Editorial Trillas, México.

ARÉVALO, R. (2008): Hostelería y turismo, recursos turísticos. Editorial Liber Factory. España.

BLANCO, M. (2008): Guía para la elaboración del Plan de Desarrollo Turístico de un territorio. Programa de desarrollo agroindustrial rural. Instituto Interamericano de cooperación para la agricultura. San José, Costa Rica.

BOTE, V. (1990): Planificación económica del turismo. Editorial Trillas. México.

CABEZA, M. (2001): «La logística en la actividad turística», Revista Venezolana de Análisis de Coyuntura, vol. VII, n² 2. pp. 257-264.

CEBRIÁN, A. et al. (2001): «La actividad turística patrimonial en la organización del territorio». En CEBRIÁN, A. (Coord.) Turismo cultural y desarrollo sostenible. Aná- 
lisis de áreas patrimoniales. Primera Edición. Servicio de publicaciones, Universidad de Murcia. España. pp. 47-70.

CHÁVEZ, J. (2005): «Coordinación de políticas públicas para el desarrollo sostenible del sector turismo en el Perú». En Serie Medio Ambiente y Desarrollo, núm. 116, Noviembre 2005. CEPAL, Santiago de Chile. Documento PDF.

CICIN-SAIN, B. y KNECHT, R. (1998): Integrated coastal and ocean management: Concepts and practices. UNESCO. Island Press, Washington, D.C.

COLSAN (2008): Los minerales del Real y su Desierto Mágico. Rutas Turísticas para descubrir la cultura y la naturaleza de una tierra prodigiosa. El Colegio de San Luis. Mapa Regional turístico. S.L.P, México.

COPLADE (2010): Plan Estatal de Desarrollo 2009-2015. Comité de Planeación del Desarrollo del Estado de San Luis Potosí. Gobierno del Estado de San Luis Potosí, México.

CORNEJO, E. (2009): «Planificación turística sostenible en la región de Coquimbo. Evaluación y aportes metodológicos», Cuadernos de Investigación Urbanística, $\mathrm{n}^{\circ}$ 65. España.

DALY, H. (1997): «Criterios operativos para el desarrollo sostenible». [Traducción]. En Daly, H. y Schutze, C. Crisis ecológica y sociedad. Editorial Germania. Valencia, España

DE GOMES, I. (2007): Experiencias de aplicación de las políticas sobre turismo sostenible. UNESCO. Uruguay. Disponible en: http://www.unesco.org.uy/ci/fileadmin/ ciencias\%20naturales/mab/turismoresponsable/07_IsisdeGomes_Par_doc.pdf [Consultado el 16 de Agosto de 2013].

ESHRAGUI, M. et al. (2010): Sustainable Ecotourism in Desert Areas in Iran: Potential and Issues. Jurnal e-Bangi. Jilid 5, Bilangan 1, Irán. pp 38-51.

GONZÁLEZ, F. (2012): Las zonas áridas y semiáridas de México y su vegetación. Secretaría de Medio Ambiente y Recursos Naturales. Instituto Nacional de Ecología. México.

GROSS, P. (1998): «Ordenamiento Territorial: El Manejo de los Espacios Rurales», EURE, vol. 24, no 73, pp. 116-118.

GUIMARÃES, R. (2010): «La insostenible domesticación del desarrollo sostenible». En Monterroso, N. y L. Zizumbo (Coord.) Contra la domesticación del turismo. Miguel Ángel Porrúa, México. pp. 7-24.

GUNN, C. (2002): Tourism Planning: Basics, Concepts, Cases. Routledge, New York.

GUTIÉRREZ, J. et al. (1986): Recursos naturales y turismo. Editorial Limusa. México.

INAFED (2010): Enciclopedia de los municipios y delegaciones de México. Estado de San Luis Potosí. Instituto Nacional para el Federalismo y el Desarrollo Municipal. Disponible en http://www.e-local.gob.mx/wb2/ELOCAL/EMM_sanluispotosi [Consultado durante Noviembre-Diciembre, 2012).

INEGI (2013a): Anuario estadístico y geográfico de San Luis Potosí 2013. Instituto Nacional de Estadística y Geografía. México.

INEGI (2013b): Sistema de Cuentas Nacionales de México. Cuenta Satélite del Turismo en México 2007-2011. Año Base 2013. Instituto Nacional de Estadística y Geografía. México. 
INE-RDS-PNUD (2001): Áreas naturales protegidas de México con decretos federales (1899-2000). Instituto Nacional de Ecología, Red Para el Desarrollo Sostenible, A.C., Programa de Naciones Unidas para el Desarrollo. México.

IVARS, J. (2003): Planificación turística de los espacios regionales en España. Editorial Síntesis, España.

KNOWLES, T. y CURTIS, S. (1999): «The Market Viability of European Mass Tourist Destinations. A Post-Stagnation Life-cycle Analysis», International Journal of Tourism Research, 1. pp. 87-96.

LEFF, E. (2007): Ecología y Capital. Racionalidad ambiental, democracia participativa y desarrollo sostenible. Siglo Veintiuno Editores. México.

LENO, F. (1991). «Los recursos turísticos en un proceso de planificación: inventario y evaluación», Papers de Turisme, n 7 , pp. 7-24.

MARTÍNEZ, J. y J. ROCA (2006): Economía Ecológica y Política Ambiental. Segunda Edición. Fondo de Cultura Económica. México.

MOLINA, S. (1986): Planificación del turismo. Editorial Nuevo Tiempo Libre, México.

MONROY, I. y CALVILlO, T. (2011): Breve historia de San Luis Potosí. Fondo de Cultura Económica, México.

MORALES, I (2012): El manejo de los recursos naturales de propiedad común en el Realejo, San Luis Potosí. Ecoturismo: intereses y procesos de negociación en un proyecto ecoturístico. Tesis de Maestría, México. El Colegio de San Luis, A.C.

MORANT, A. et al. (1996): «Oferta turística». En Pedreño, A. et al. (Coord.) Introducción a la Economía del Turismo en España. Civitas. Madrid.

OMT (1995): Carta del turismo sostenible de Lanzarote, 1995. Conferencia Mundial de Turismo Sostenible, Lanzarote, España, 27-28 de Abril de 1995. Disponible en www. turismo-sostenible.org/docs/Carta-del-Turismo-Sostenible.pdf [Consultado el 07 de Febrero de 2014].

OMT (1996): Agenda 21 for the travel and tourism industry. Towards environmentally sustainable development. WTO/Word Travel Tourism Council/Word Earth. Disponible en http://www.wttc.org/stratdev/agenda21.asp [Consultado el 26 de Octubre de 2010].

OMT (2001): Cooperación entre los sectores público y privado. Por una mayor competitividad del turismo. Consejo Empresarial OMT. Organización Mundial del Turismo. Madrid.

OMT (2006): Agenda para planificadores locales: turismo sostenible y gestión municipal. Organización Mundial del Turismo. Madrid, España.

OMT (2013): Panorama OMT del turismo mundial. Organización Mundial del Turismo, Edición 2013. Documento PDF.

ORTEGA, J. (2000): Los horizontes de la geografía. Editorial Ariel, S.A. Barcelona, España.

OSORIO, M. (2006): «La planificación turística. Enfoques y modelos», Quivera, vol. 8, $n^{\circ} 1$, pp. 291-314.

PARDELLAS, X. y PADÍN, C. (2004): «Una propuesta de turismo sostenible para el Municipio de Caldas de Reis (Pontevedra), Cuadernos de Turismo, nº 13, pp. 107-125. 
PIERRI, N. (2001): «El proceso histórico y teórico que conduce a la propuesta del DS». En Pierri y Foladori (2001) ¿Sostenibilidad? Desacuerdos sobre el desarrollo sostenible. Uruguay: Trabajo y Capital.

PITARCH, D. (2009). «Los recursos territoriales turísticos: su gestión y organización en entornos locales». En Noguera, J. et al., Gestión y promoción del desarrollo local. Colección Desarrollo Territorial. Publicaciones de la Universidad de Valencia. Guada Impresores. España. pp. 443-474.

PNUD (2006): Informe sobre Desarrollo Humano en San Luis Potosí, 2000-2005. Programa de las Naciones Unidas para el Desarrollo, México.

PNUMA (2003): Instrumentos Económicos y Política Fiscal. Programa de Naciones Unidas para el Medio Ambiente. XIV Reunión del Foro de Ministros de Medio Ambiente en América Latina y el Caribe. Del 20 al 25 de Noviembre. Ciudad de Panamá.

POF (2000): Decreto que declara Área Natural Protegida, bajo la modalidad de Reserva Estatal del Paisaje Cultural denominado Huiricuta, los Lugares Sagrados y la Ruta Histórico Cultural del Pueblo Huichol. Viernes 27 de Octubre de 2000. Periódico Oficial del Gobierno del Estado de San Luis Potosí, México.

POF (2009): Programa Regional Turístico de los Pueblos Mineros del Altiplano Potosino. Jueves 12 de Febrero de 2009. Periódico Oficial del Gobierno del Estado de San Luis Potosí. México.

RAMÍREZ, M. (1992): Teoría General de Turismo. 2a . Edición. Editorial Diana. México. REQUEJO, J. (2004): «Turismo y ordenación del territorio: ¿quién necesita a quién?». En Comunidad Virtual de Gobernabilidad y Liderazgo. [Documento electrónico]. Publicado el 28 de Noviembre de 2004. Colombia. sp.

ROMERO, H. (1986): Enciclopedia Mexicana del Turismo. Vol. 3. Instituto Politécnico Nacional. Editorial Limusa. México.

SACHS, W. (1997): «Arqueología de la idea de desarrollo». [Traducción]. En Economía y Medio Ambiente. Economía Informa, Número 253, Diciembre-Enero. Facultad de Economía, UNAM. México. pp. 12-28.

SALINAS, E. y LA O, A. (2006): «Turismo y sostenibilidad: de la teoría a la practica en Cuba», Cuadernos de Turismo, no 17, pp. 201-221.

SÁNCHEZ-CRISPÍN, A. (2001): «El territorio y nuevas formas del turismo en México: el caso de Mapimí, Durango». En México en su unidad y diversidad territorial. Tomo II. INEGI. México, pp. 628-640.

SCHULTE, S. (2003): «Guía conceptual y metodológica para el desarrollo y la planificación del sector turístico». En Serie Manuales, núm. 25, Septiembre 2003. CEPAL, Santiago de Chile.

SECRETARÍA DE TURISMO DE SAN LUIS POTOSÍ (2010): Perfil del visitante. Invierno 2010. Región Altiplano. Dirección de Planeación, Información y Análisis. Gobierno del Estado de San Luis Potosí. México.

SECRETARÍA DE TURISMO DE SAN LUIS POTOSÍ (2012a): Perfil del visitante. Semana Santa 2012. Altiplano Potosino. Dirección de Planeación, Información y Análisis. Gobierno del Estado de San Luis Potosí. México. 
SECRETARÍA DE TURISMO DE SAN LUIS POTOSÍ (2012b): Perfil del visitante. Verano 2012. Región Altiplano. Dirección de Planeación, Información y Análisis. Gobierno del Estado de San Luis Potosí. México.

SECTUR (2007): Cómo desarrollar productos turísticos competitivos. Fascículo 3. Secretaría de Turismo. México.

SECTUR (2008): El mercado del turismo de naturaleza en México. Consejo de promoción turística. Gobierno Federal, México. Disponible en: http://www.sectur.gob.mx/work/ models/sectur/Resource/15360/MarcelaCamacho.pdf [Consultado el 26 de junio de 2014].

SEDECO (2013): Estudios: El Estado de San Luis Potosí. Secretaría de Desarrollo Económico. Gobierno del Estado de San Luis Potosí, México. Disponible en http://www. sdeslp.gob.mx/estudios/perfiles/Estado\%20de\%20SLP.pdf. [Consultado el 26 de junio de 2014].

SEDESORE (2010): Política social y combate a la pobreza: Desarrollo social. Programas Sectoriales 2010-2015: Eje 1. Secretaría de Desarrollo Social y Regional. Gobierno del Estado de San Luis Potosí, México.

SEGUÍ, M. (2006): «La difícil implantación de modelos de turismo sostenible en países en vías de desarrollo a través de la cooperación», Aportes y Transferencias, vol. 10, $\mathrm{n}^{\mathbf{o}} 1$, pp. 78-87.

SEMARNAT-INE-CONAP (2001): Áreas naturales protegidas de México con decretos estatales. Volumen 2. Secretaría del Medio Ambiente y Recursos Naturales, Instituto Nacional de Ecología, Comisión Nacional de Áreas Protegidas. México.

VÁZQUEZ, V. et al. (2008): Informe técnico del proyecto de Investigación «Potencial natural y socioeconómico para el desarrollo del ecoturismo en el estado de San Luis Potosí. Fondos Mixtos CONACyT- Gobierno del Estado de San Luis Potosí. Clave 62933, Disponible en PDF.

VÁZQUEZ, V. y P. BENITO (2009): Turismo y territorio en México: alternativas en el Altiplano Potosino. Biblio 3W. Revista Bibliográfica de Geografía y Ciencias Sociales, vol. XIV, ${ }^{\circ} 813$.

ZIZUMBO, L. (2010): «Turismo y economía social, nuevas formas organizativas de trabajo para el desarrollo sostenible». En Monterroso, N. y L. Zizumbo (Coord.) Contra la domesticación del turismo. Miguel Ángel Porrúa, México. pp. 25-74.

\section{Enlaces electrónicos y bases de datos:}

INEGI. Censo de Población y Vivienda 2010: http://www.inegi.org.mx/est/contenidos/ proyectos/ccpv/cpv2010/Default.aspx

Secretaría de Turismo del Estado de San Luis Potosí

http://www.turismoslp.com.mx/ 